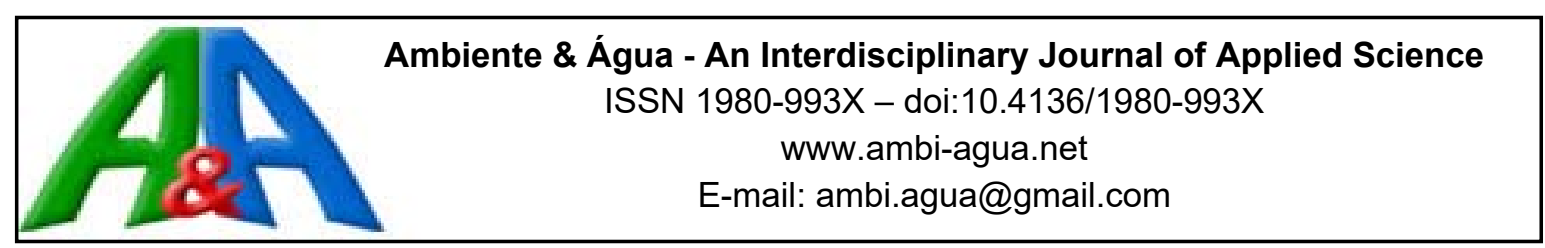

\title{
Atributos físicos e estoque de carbono do solo em áreas de Terra Preta Arqueológica da Amazônia
}

\author{
doi:10.4136/ambi-agua.1890 \\ Received: 11 Mar. 2016; Accepted: 31 Jan. 2017 \\ José Maurício da Cunha ${ }^{{ }^{*}}$; Denilton Carlos Gaio ${ }^{2}$;
Milton César Costa Campos ${ }^{1}$; Marcelo Dayron Rodrigues Soares $^{1}$;
Douglas Marcelo Pinheiro da Silva ${ }^{1}$; Alan Ferreira Leite de Lima ${ }^{1}$ \\ ${ }^{1}$ Universidade Federal do Amazonas (UFAM), Humaitá, AM, Brasil \\ Instituto de Educação, Agricultura e Ambiente (IEAA) \\ ${ }^{2}$ Universidade Federal de Mato Grosso (UFMT), Cuiabá, MT, Brasil \\ Programa de Pós-Graduação em Física Ambiental \\ *Autor correspondente: e-mail: maujmc@gmail.com, \\ dcgaio@ufmt.br, mcesarsolos@gmail.com, marcelo.dayron@gmail.com, \\ dougllas.marcelo@gmail.com, ala_leite@hotmail.com
}

\section{RESUMO}

Para se avaliar a qualidade do solo e a sustentabilidade em ambientes de Terra Preta Arqueológica da Amazônia, é importante a caracterização dos impactos de uso de solo dos diferentes tipos de cobertura. Sendo assim, o objetivo deste trabalho foi avaliar os atributos físicos e o carbono orgânico em áreas de Terra Preta Arqueológica, no município de Novo Aripuanã, AM, sob os cultivos feijão guandu (Cajanus cajan) e pastagem, em comparação com a cobertura de floresta, com base em técnicas de estatística tradicional univariada e multivariada e de geoestatística. Para isso foram delimitadas malhas com espaçamentos regulares e 88 pontos amostrais georreferenciados por malha. Foram coletadas amostras em blocos de solo com estrutura preservada e anéis volumétricos, para a determinação das propriedades físicas e do carbono orgânico do solo. O feijão guandu e pastagem diferem estatisticamente da floresta, que apresentaram características de estabilidade dos agregados acima da média, mas características texturais e carbono orgânico abaixo da média. O modelo exponencial, pelo semivariograma escalonado, mostrou que atributos físicos do solo apresentaram predominância, com grau de dependência de forte a moderado, sendo a área sob feijão guandu com maior variabilidade dos atributos do solo.

Palavras-chave: Aripuanã, química e física do solo, TPA sob floresta, usos do solo.

\section{Physical attributes and carbon stock of soils of Archaeological Dark Earth of the Amazonia}

\begin{abstract}
In order to evaluate soil quality and sustainability in Amazon Archaeological Dark Earth environments, it is important to characterize the impacts of the use of different cover types. The objective of this work was therefore to evaluate the physical attributes and organic carbon content in areas of "Terra Preta Arqueológica", in the municipality of Novo Aripuanã, AM, under the cultivation of pigeon pea (Cajanus cajan) and pasture, in comparison with forest
\end{abstract}


cover, based on traditional univariate and multivariate statistical techniques and geostatistics. In order to accomplish this, grids with regular spacing and samples with 88 georeferenced points per grid were delimited. Samples of soil blocks with preserved structure and volumetric rings were collected to determine physical properties and organic carbon content. The pigeon pea and pasture soils differ statistically from that of the forest and presented above-average aggregate stability, but texture and organic carbon characteristics were below average. The exponential model showed that the physical attributes of the soil predominated, with a strong to moderate degree of dependence, with the area under pigeon pea presenting the greatest variability of soil attributes.

Keywords: Aripuanã, land use, TPA under forest.

\section{INTRODUÇÃO}

As Terras Pretas Arqueológicas (TPA) são solos cuja característica marcante é a presença de coloração escura e artefatos cerâmicos e/ou líticos indígenas incorporados à matriz dos horizontes superficiais do solo (Kämpf e Kern, 2005). Elas apresentam uma elevada fertilidade natural incorporada à matriz do horizonte, sendo encontrada na região Amazônica em forma de manchas em meio a uma vasta extensão de terra que, na grande maioria, extremamente pobre em nutrientes.

Muitas dessas áreas são substituídas por atividades voltadas para fins industriais ou produção de alimentos. No entanto, solos preservados em seu estado natural, sob vegetação nativa, apresentam características físicas adequadas ao desenvolvimento das plantas (Calonego et al., 2012). Os usos de práticas agrícolas inadequada e de forma intensiva promovem alterações em suas propriedades originais (Rozane et al., 2010; Viana et al., 2011; Rossetti e Centurion, 2015), que por sua vez, a gestão dos solos de forma sustentável, com práticas de conservações apropriadas, é necessária a fim de que se possa evitar sua maior degradação (White et al., 2012).

Normalmente solos em ambientes naturais, por não sofrer interferência humana, apresentam menores densidade do solo e maiores volumes total de poros (Calonego et al., 2012), sendo que a densidade do solo apresenta correlação positiva com a microporosidade e negativa com a macroporosidade e porosidade total (Cunha et al., 2011), fatores que influenciam no processo de compactação do solo (Silveira et al., 2010).

Outros atributos usados para avaliar a qualidade física do solo são a resistência do solo a penetração (RP) e a umidade do solo, que por sua vez estão relacionados com crescimento e desenvolvimento radicular das plantas (Silveira et al., 2010). Em solos de ambientes naturais, foi observado menor RP em relação ao solo cultivado, ou seja, a densidade do solo é maior sob as plantas de cobertura, que reflete na maior resistência do solo à penetração, que por sua vez, tem apresentado correlação negativa com o teor de carbono orgânica no solo (Cunha et al., 2011; Silva et al., 2012).

A matéria orgânica tem influência direta e indiretamente aos atributos do solo (Viana et al., 2011) e o seu estudo em agro-ecossistema brasileiro é base para que se alcance a sustentabilidade agrícola (Cunha et al., 2011). É sabido também que práticas de uso e manejo dos solos, e suas variações, interferem no equilíbrio natural dos ecossistemas, alterando os componentes orgânicos tanto em quantidade como em qualidade (Melo e Schaefer, 2009). Por outro lado, o teor de carbono orgânico do solo sob floresta é maior do que em solos adjacentes que por sua vez favorece na estrutura do solo (Silva et al., 2008; Andrade et al., 2009).

$\mathrm{O}$ uso de práticas agrícolas tem efeito direto sobre os atributos físicos do solo, além de expressivas interferências no teor de carbono orgânico do solo (Matos et al., 2008; Rozane et 
al., 2010; Iori et al., 2012). Nesse sentido, a variabilidade espacial dos atributos físicos e químicos do solo, em ambientes naturais e transformados, torna-se importante para o entendimento dos processos de evolução a formação do solo e variações desses atributos para diferentes sistemas de uso e manejo do solo (Oliveira et al., 2013; 2015a; Aquino et al., 2015).

Há a necessidade de estudos relacionados aos atributos do solo de TPAs quanto a suas modificações em determinados usos e manejos dos solos, principalmente quando se compara com ambientes sob floresta. Pesquisa tem avaliado os atributos do solo sobre diferentes ambientes em ralação ao uso do solo sobre TPA (Oliveira et al., 2015b), identificando comportamento muito característico dos atributos do solo em ambientes de TPA. No entanto, não há estudos relacionados aos atributos do solo sobre o uso de TPA em comparação aos ambientes de floresta preservados em áreas de TPA.

Portanto, o objetivo deste trabalho foi avaliar os atributos físicos e o estoque de carbono em áreas de Terra Preta Arqueológica sob os cultivos feijão Guandu (FJ) (Cajanus cajan) e pastagem (PT), em comparação com a área de floresta (FN), utilizando técnicas de estatística tradicional univariada e multivariada e da geoestatística.

\section{MATERIAL E MÉTODOS}

O estudo localizou-se no município de Novo Aripuanã (Figura 1), Amazonas, Brasil, entre agosto de 2014 a julho de 2016, situado ao longo da rodovia Transamazônica (BR-230). O clima da região é Clima Tropical Chuvoso, apresentando um período seco de pequena duração. A pluviosidade média varia entre 2,250 e $2,750 \mathrm{~mm}$ ao ano, com período chuvoso entre outubro a junho. As temperaturas médias anuais variam entre $25^{\circ} \mathrm{C}$ e $27^{\circ} \mathrm{C}$ e a umidade relativa fica entre 85 e $90 \%$ (Brasil, 1978).
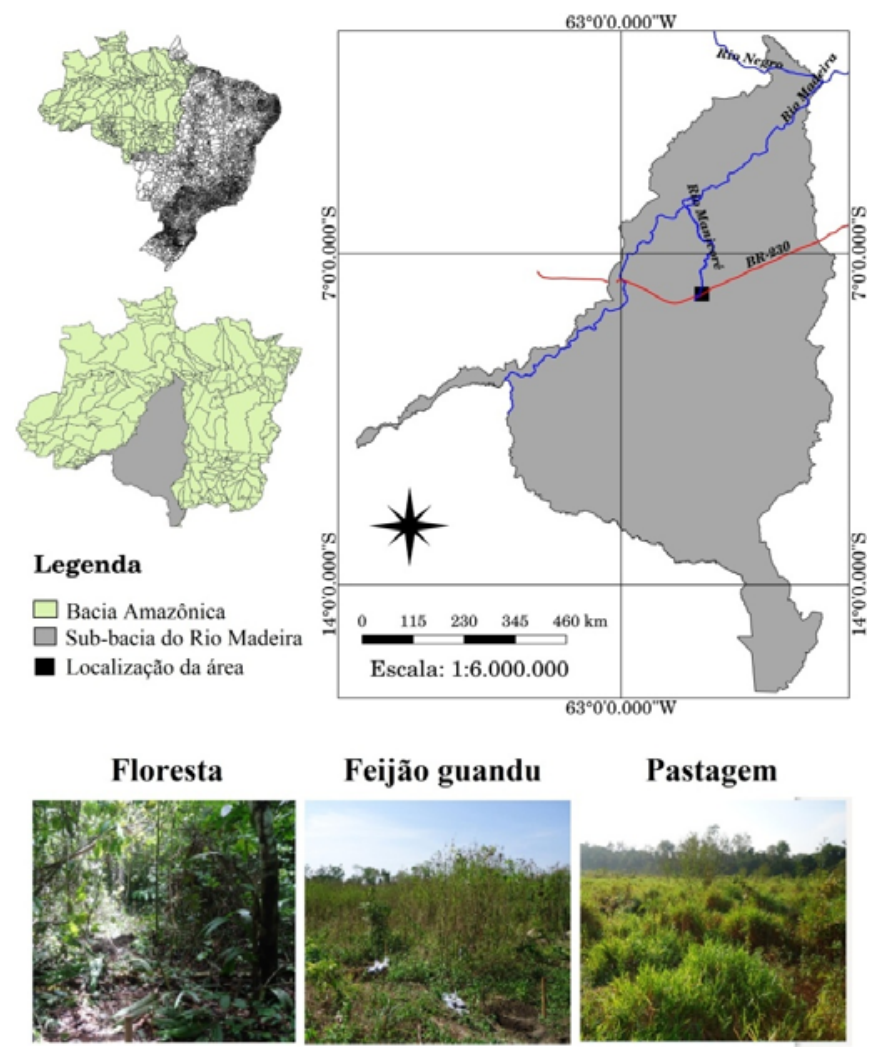

Figura 1. Localização da área de estudo.

A área de TPA sob floresta natural (FN) vem sendo preservado a mais de vinte e cinco anos, com início de recuperação florestal natural com árvores de porte mediano, chegando a 
apresentar de até quinze metros de altura. Já os usos de TPAs sob cultivo de feijão Guandu (Cajanus cajan) (FJ) e pastagem Brachiaria brizanta (PT), abrigou nos últimos vinte e cinco anos os cultivos milho, feijão e melancia. Nos últimos oito meses, foi inserido o pasto para atividades de pecuária, preservando uma área do feijão Guandu.

Foram delimitadas três malhas amostrais com 88 pontos de coleta de material por malha, sendo 90 pontos de coleta da área do feijão Guandu. As dimensões das malhas foram de $2.500 \mathrm{~m}^{2}$ para a FN, $1.700 \mathrm{~m}^{2}$ para o FJ e $4.800 \mathrm{~m}^{2}$ para a PT, com espaçamentos regulares entre os pontos de coleta do solo de $6 \times 6 \mathrm{~m}$, de $4 \times 5 \mathrm{~m}$ e de $8 \times 8 \mathrm{~m}$, respectivamente. A escolha das dimensões das malhas foi definida no campo, conforme avaliada as dimensões da área de TPA e a respectiva cobertura representativa do solo. Foram coletados blocos de solos com estrutura preservada e anéis volumétricos nas camadas $0,0-0,05 \mathrm{~m}, 0,05-0,10 \mathrm{~m}$ e 0,10-0,20 m, para a determinação das propriedades físicas estruturais, granulométricas e mecânicas do solo, assim como a matéria orgânica. Esses pontos foram georreferenciados com um equipamento de GPS para o mapeamento das áreas, e posteriormente utilizado nas análises geoestatística.

As amostras com estrutura preservada em forma de torrão de solo foram secadas à sombra e posteriormente destorroadas, de forma manual, e passadas em peneira de 9,51 $\mathrm{mm}$ de diâmetro e retidas na peneira de $4,76 \mathrm{~mm}$, para as análises relativas à estabilidade de agregados. As amostras retidas na peneira de $2,00 \mathrm{~mm}$ foram utilizadas nas análises granulométricas e de matéria orgânica, após passadas em peneira de $250 \mu \mathrm{m}$.

O método empregado para a separação e estabilidade dos agregados foi determinado segundo Kemper e Chepil (1965), com modificações nas seguintes classes de diâmetro: 4,76-2,0 mm; 2,0-1,0 mm; 1,0-0,50 mm; 0,50-0,25 mm;0,25-0,125 mm;0,125-0,063 mm. Os agregados foram colocados em contato com a água sobre a peneira de 2,00 $\mathrm{mm}$ e submetidos à agitação vertical em aparelho Yoder (SOLOTEST, Bela Vista, São Paulo, Brasil) por 15 min. Os materiais retidos em cada classe de peneira foram colocados em estufa a $105^{\circ} \mathrm{C}$, e em seguida mensurada as respectivas massas em uma balança digital.

Os resultados foram expressos em termos da porcentagem dos agregados retidos em cada uma das classes das peneiras e a estabilidade dos agregados avaliados pelo diâmetro médio ponderado (DMP) e o diâmetro médio geométrico (DMG), conforme Equações 1 e 2.

$$
\begin{aligned}
& D M P=\frac{\sum_{i=1}^{N} n_{i} D_{i}}{\sum n_{i}} \\
& D M G=10^{\frac{\sum_{i=1}^{N} n_{i} \log D_{i}}{\sum n_{i}}}
\end{aligned}
$$

em que:

$\mathrm{n}_{\mathrm{i}}=\%$ dos agregados retidos em uma determinada peneira;

$\mathrm{D}_{\mathrm{i}}=$ diâmetro médio de uma determinada peneira;

$\mathrm{N}=$ número de classes de peneiras.

A análise granulométrica foi realizada pelo método da pipeta, utilizando uma solução normal de $\mathrm{NaOH}$ como dispersante químico e agitação mecânica em aparato de alta rotação por 15 min, seguindo metodologia proposta pela Embrapa (2011). A fração argila foi separada por sedimentação, a areia por tamisação e o silte foi calculado por diferença.

Para as determinações da densidade do solo (Ds), macroporosidade (MaP) e microporosidade (MiP), volume total de poros (VTP) e umidade gravimétrica (Ug), as amostras de anéis volumétricos foram saturadas por meio da elevação gradual de uma lâmina de água numa bandeja plástica. Após a saturação, as amostras foram pesadas e levadas à mesa de tensão para determinação da MiP, sendo submetidas a uma tensão de 0,006 MPa (Embrapa, 2011).

Após atingirem o equilíbrio em um potencial matricial de $0,006 \mathrm{MPa}$, as amostras foram 
novamente pesadas e, em seguida, foram feitas as medidas da resistência do solo à penetração (RP), utilizando-se um penetrógrafo eletrônico modelo MA-933, marca Marconi. Posteriormente, as amostras foram levadas à estufa a $105^{\circ} \mathrm{C}$ para a determinação da Ug, Ds e VTP, pelo método do anel volumétrico, e a MaP foi determinada pela diferença entre VTP e MiP (Embrapa, 2011).

O carbono orgânico $(\mathrm{CO})$ foi determinado pelo método de Walkley-Black, modificado por Yeomans e Bremner (1988). A matéria orgânica é determinado pelo produto do CO com 1,724 (Embrapa, 2011). Já o estoque de carbono (EC) é definido pela Equação 3.

$$
E C=D s \times h \times C O
$$

em que:

EC: é estoque de carbono $\left(\mathrm{Mg} \mathrm{ha}^{-1}\right)$;

Ds: é densidade do solo $\left(\mathrm{Mg} \mathrm{m}^{-3}\right)$;

h: é a espessura da camada de solo amostrada $(\mathrm{cm})$; e

CO: é teor de C (\%).

Após a determinação dos atributos físicos e da matéria orgânica do solo, foram feitas análise estatística univariada e multivariada. A análise de variância univariada (ANOVA) foi utilizada para comparar médias dos atributos individualmente utilizando do teste de Tukey, tendo como referência a área de TPA sob floresta. Em seguida foi utilizada a análise de variância multivariada (MANOVA), através da análise fatorial e de agrupamento, a fim de encontrar significância estatística dos conjuntos dos atributos do solo que mais discriminam os ambientes, com referência ao ambiente sob floresta, obtendo como resposta atributos que sofrem maior influência sobre o uso do solo.

A adequação da análise fatorial foi feita pela medida de Kaiser-Meyer-Olkin (KMO), que avalia as correlações simples e parciais das variáveis, e pelo teste de esfericidade de Barlett, ao qual se pretende rejeitar a igualdade entre a matriz correlação com a identidade. A extração dos fatores foi feita pelas componentes principais, incorporando as variáveis que apresentaram comunalidades igual ou superior a cinco. A escolha do número de fatores a ser utilizados foi feito pelo critério de Kaiser (fatores que apresentam autovalores superior a 1). A fim de simplificar a análise fatorial, foi feita a rotação ortogonal (Varimax) dos fatores e representada em um plano fatorial das duas componentes.

A análise geoestatística foi feita com base no semivariograma experimental, estimado pela Equação 4.

$$
\hat{\gamma}(h)=\frac{1}{2 n(h)} \sum_{i=1}^{n(h)}\left[Z\left(x_{i}\right)-Z\left(x_{i}+h\right)\right]^{2}
$$

em que:

$\hat{y}(h)$ : é o valor da semivariância para uma distância h;

$\mathrm{n}(\mathrm{h})$ : é o número de pares envolvidos no cálculo da semivariância;

$\mathrm{Z}\left(\mathrm{x}_{\mathrm{i}}\right)$ : é o valor do atributo $\mathrm{Z}$ na posição $\mathrm{x}_{\mathrm{i}}$; e

$\mathrm{Z}\left(\mathrm{x}_{\mathrm{i}}+\mathrm{h}\right)$ : é o valor do atributo $\mathrm{Z}$ separado por uma distância $\mathrm{h}$ da posição $\mathrm{X}_{\mathrm{i}}$.

Para a análise do grau de dependência espacial das variáveis em estudo, utilizou-se a classificação de Cambardella et al. (1994), em que as propriedades do solo são consideradas com dependência espacial forte se a razão $\left[\frac{C_{0}}{C_{0}+C}\right]$ for $\leq 25$. Se essa razão estiver entre $26 \%$ a $75 \%$, a dependência espacial é considerada moderada, enquanto que se a propriedade do solo for maior que $75 \%$ a aproximadamente $95 \%$, classificam-se como dependência espacial fraca. 
Com base nos parâmetros dos semivariogramas experimentais dos atributos do solo, foram utilizados os semivariogramas escalonados com o objetivo de reduzi-los à mesma escala, facilitando a comparação entre resultados de diferentes variáveis (Ceddia et al., 2009). A escolha do modelo de semivariograma escalonado foi utilizada pelo menor resíduo. Os modelos utilizados nos ajustes do semivariograma escalonado foram o esférico (Equação 5) e o exponencial (Equação 6).

$$
\begin{aligned}
& \hat{y}(h)=C_{0}+C_{1}\left[\frac{3}{2}\left(\frac{h}{a}\right)-\frac{1}{2}\left(\frac{h}{a}\right)^{3}\right], \text { se } 0<h<a \\
& \hat{y}(h)=C_{0}+C_{1}=\left[1-\exp \left(-3 \frac{h}{a}\right)\right], 0<h<d
\end{aligned}
$$

em que:

$\mathrm{C}_{0}$ : é o efeito pepita;

$\mathrm{C}_{0}+\mathrm{C}_{1}$ : é o patamar;

$\left[\left(\mathrm{C}_{0} /\left(\mathrm{C}_{0}+\mathrm{C}_{1}\right)\right) \times 100\right]$ : é o grau de dependência espacial (GDE);

h: é a distância de separação entre duas observações; e

a: é o alcance do semivariograma. O ajuste do semivariograma foi feito com base no melhor coeficiente de determinação $\left(\mathrm{R}^{2}\right)$ e menor soma dos quadrados dos resíduos (SQRes).

A análise estatística ANOVA e MANOVA foi feita no programa computacional StatSoft, (2004), enquanto que a análise geoestatísitca foi utilizado o programa GS+ 7.0 (Robertson, 1998).

\section{RESULTADOS E DISCUSSÃO}

A estatística descritiva para os atributos em comparação aos usos do solo em áreas Terra Preta Arqueológica (TPA) é apresentada nas Tabelas 1, 2 e 3, para as respectivas camadas 0,00-0,05 m, 0,05-0,10 m e 0,10-0,20 m.

Os coeficientes de assimetria apresentaram valores próximos à zero, com exceção das classes de agregados $<1,00 \mathrm{~mm}$ para o uso de TPA sob pastagem, nas camadas $0,00-0,05 \mathrm{~m}$ e 0,05-0,10 m. Os resultados tendem a apresentar valores simétricos nos ambientes em estudo. Já o coeficiente de curtose, boa parte dos atributos apresentaram uma distribuição platicúrtica (distribuição mais achatada que a distribuição normal).

As medidas de média e mediana, devido aos dados apresentar uma distribuição simétrica, ambos mostraram valores muito próximo para todos os atributos e em suas respectivas camadas, o que justifica distribuições normais ou aproximadamente normais. Pelo teste de Kolmogorov-Smirnov, mostraram-se variações entre os ambientes e propriedades nas respectivas camadas. Mesmo assim, erros de análises em relação aos testes de hipóteses são mínimos, quando avaliados em relação a uma distribuição normal. Por outro lado, a normalidade dos dados não é um pressuposto necessário para a aplicação de técnica geoestatística, mas sim que a distribuição não apresente caudas muito alongadas, o que poderia comprometer a análise (Isaaks e Srivastava, 1989; Cressie, 1991).

Os atributos granulométricos apresentaram diferença significativa entre os ambientes estudados e com dominância na fração de areia, em contraste a resultados encontrados por Oliveira et al. (2015a), que evidenciou áreas de TPA sob cultivo com dominância na fração silte para a camada de 0,00-0,20 m. A área de TPA sob floresta evidenciou menores teores de areia para as três profundidades, e maiores teores de silte e argila, com exceção da fração argila na camada $0,10-0,20 \mathrm{~m}$, obtendo com isso menor valor. 
Tabela 1. Teste de média e estatística descritiva dos atributos do solo na profundidade de 0,00-0,05 m para as áreas com diferentes usos na região de Novo Aripuanã, Amazonas.

\begin{tabular}{|c|c|c|c|c|c|c|c|c|c|c|c|c|c|c|c|c|}
\hline \multirow{2}{*}{$\begin{array}{l}\text { Estatística } \\
\text { Descritiva }\end{array}$} & Ds & $\mathrm{MaP}$ & MiP & VTP & Ug & \multirow{2}{*}{$\begin{array}{c}\mathrm{RP} \\
\mathrm{MPa}\end{array}$} & \multirow{2}{*}{$\begin{array}{c}\mathrm{CO} \\
\mathrm{g} \mathrm{kg}^{-3}\end{array}$} & \multirow{2}{*}{$\begin{array}{c}\mathrm{EC} \\
\mathrm{t} \mathrm{ha}^{-1}\end{array}$} & DMG & DMP & \multirow{2}{*}{$>2,00$} & \multirow{2}{*}{$2,00-1,00$} & \multirow{2}{*}{$<1,00$} & \multirow{2}{*}{ Areia } & \multirow{2}{*}{$\begin{array}{l}\text { Silte } \\
\mathrm{g} \mathrm{kg}^{-1}\end{array}$} & \multirow{2}{*}{ Argila } \\
\hline & $\mathrm{mg} \mathrm{m}^{-3}$ & \multicolumn{3}{|c|}{$\%$} & & & & & \multicolumn{2}{|c|}{$\mathrm{mm}$} & & & & & & \\
\hline \multicolumn{17}{|c|}{ Floresta } \\
\hline Média & $1,27 \mathrm{~A}$ & $26,50 \mathrm{~A}$ & $30,90 \mathrm{~A}$ & $57,40 \mathrm{~A}$ & $24,40 \mathrm{~A}$ & $0,40 \mathrm{~B}$ & $22,96 \mathrm{~B}$ & $145,80 \mathrm{~B}$ & $2,74 \mathrm{~A}$ & $3,10 \mathrm{~A}$ & $91,19 \mathrm{~A}$ & $1,29 \mathrm{~B}$ & $8,05 \mathrm{~B}$ & $701,10 \mathrm{~B}$ & $203,40 \mathrm{~A}$ & $95,50 \mathrm{~A}$ \\
\hline Mediana & 1,27 & 26,10 & 30,70 & 57,50 & 24,30 & 0,37 & 22,17 & 141,70 & 2,76 & 3,10 & 91,17 & 1,17 & 7,43 & 697,30 & 199,50 & 94,60 \\
\hline DP & 0,08 & 3,59 & 2,19 & 3,30 & 2,40 & 0,13 & 4,50 & 25,80 & 0,26 & 0,12 & 3,96 & 0,73 & 3,88 & 27,40 & 27,60 & 16,02 \\
\hline CV (\%) & 6,30 & 13,55 & 7,09 & 5,75 & 9,84 & 32,50 & 19,60 & 17,82 & 9,49 & 3,87 & 4,34 & 56,59 & 48,20 & 3,91 & 13,57 & 16,77 \\
\hline Assimetria & 0,05 & 0,11 & 0,16 & $-0,03$ & 0,54 & 0,46 & 0,29 & 0,40 & $-0,58$ & $-0,57$ & $-0,56$ & 0,65 & 0,82 & $-0,15$ & $-0,05$ & $-0,03$ \\
\hline Curtose & 0,17 & $-0,16$ & 0,00 & 0,02 & 0,68 & $-0,02$ & $-0,53$ & $-0,02$ & $-0,22$ & $-0,29$ & $-0,29$ & $-0,21$ & 0,35 & 0,00 & $-0,38$ & $-0,50$ \\
\hline K-S & 0,20 & 0,20 & 0,20 & 0,20 & 0,20 & 0,03 & 0,20 & 0,20 & 0,06 & 0,20 & 0,20 & 0,20 & 0,20 & 0,20 & 0,20 & 0,20 \\
\hline \multicolumn{17}{|c|}{ Feijão Guandu } \\
\hline Média & $1,26 \mathrm{~A}$ & $26,40 \mathrm{~A}$ & $30,80 \mathrm{~A}$ & $57,20 \mathrm{~A}$ & $24,90 \mathrm{~A}$ & $0,49 \mathrm{~A}$ & $33,93 \mathrm{~A}$ & $213,76 \mathrm{~A}$ & $2,24 \mathrm{~B}$ & $2,80 \mathrm{~B}$ & 80,86 B & $2,58 \mathrm{~A}$ & $17,36 \mathrm{~A}$ & $732,50 \mathrm{~A}$ & $194,90 \mathrm{~A}$ & $72,60 \mathrm{~B}$ \\
\hline Mediana & 1,26 & 27,00 & 30,80 & 57,02 & 24,70 & 0,44 & 33,02 & 210,30 & 2,29 & 2,90 & 83,55 & 2,54 & 14,58 & 734,60 & 192,50 & 72,40 \\
\hline DP & 0,14 & 5,40 & 3,30 & 4,70 & 3,80 & 0,21 & 7,34 & 40,90 & 0,58 & 0,37 & 12,26 & 1,58 & 11,41 & 39,40 & 35,21 & 18,50 \\
\hline CV (\%) & 11,11 & 20,45 & 10,71 & 8,22 & 15,26 & 42,86 & 21,63 & 19,35 & 25,89 & 13,21 & 15,16 & 61,24 & 65,73 & 5,38 & 18,07 & 25,48 \\
\hline Assimetria & $-0,04$ & $-0,36$ & 0,19 & 0,12 & 0,40 & 0,78 & 0,04 & $-0,14$ & $-0,24$ & $-0,63$ & $-0,60$ & 0,66 & 0,59 & $-0,24$ & 0,22 & 0,16 \\
\hline Curtose & $-0,43$ & $-0,27$ & $-0,22$ & $-0,22$ & $-0,08$ & 0,30 & $-0,33$ & 0,00 & $-1,09$ & $-0,40$ & $-0,51$ & $-0,04$ & $-0,55$ & $-0,41$ & $-0,14$ & $-0,15$ \\
\hline K-S & 0,20 & 0,20 & 0,20 & 0,20 & 0,20 & 0,01 & 0,20 & 0,20 & 0,00 & 0,00 & 0,01 & 0,20 & 0,00 & 0,20 & 0,20 & 0,20 \\
\hline \multicolumn{17}{|c|}{ Pastagem } \\
\hline Média & $1,22 \mathrm{~A}$ & $27,70 \mathrm{~A}$ & $30,90 \mathrm{~A}$ & $58,60 \mathrm{~A}$ & $25,30 \mathrm{~A}$ & $0,49 \mathrm{~A}$ & $22,77 \mathrm{~B}$ & $138,90 \mathrm{~B}$ & $2,64 \mathrm{~A}$ & $3,10 \mathrm{~A}$ & $90,86 \mathrm{~A}$ & $0,93 \mathrm{C}$ & $8,47 \mathrm{~B}$ & $741,40 \mathrm{~A}$ & $180,50 \mathrm{~B}$ & $78,10 \mathrm{~B}$ \\
\hline Mediana & 1,22 & 28,30 & 31,10 & 58,30 & 25,30 & 0,44 & 22,51 & 133,30 & 2,65 & 3,11 & 91,85 & 0,80 & 7,34 & 745,60 & 180,40 & 78,00 \\
\hline DP & 0,10 & 6,60 & 3,60 & 4,50 & 2,60 & 0,22 & 4,25 & 28,40 & 0,26 & 0,13 & 4,33 & 0,56 & 4,28 & 29,40 & 34,30 & 18,97 \\
\hline CV (\%) & 8,20 & 23,83 & 11,65 & 7,68 & 10,28 & 44,90 & 18,66 & 20,42 & 9,85 & 4,19 & 4,77 & 60,22 & 50,53 & 3,97 & 19,00 & 24,29 \\
\hline Assimetria & 0,06 & $-0,22$ & 0,40 & 0,16 & 0,12 & 0,68 & 0,27 & 0,49 & $-0,48$ & $-1,00$ & $-1,00$ & 0,60 & 1,17 & $-0,42$ & $-0,25$ & 0,08 \\
\hline Curtose & $-0,16$ & $-0,36$ & $-0,40$ & $-0,72$ & $-0,51$ & 0,01 & $-0,35$ & $-0,02$ & $-0,18$ & 0,67 & 0,65 & $-0,51$ & 0,85 & 0,22 & $-0,06$ & $-0,25$ \\
\hline K-S & 0,20 & 0,20 & 0,01 & 0,20 & 0,20 & 0,06 & 0,20 & 0,20 & 0,20 & 0,01 & 0,01 & 0,04 & 0,01 & 0,08 & 0,20 & 0,20 \\
\hline
\end{tabular}

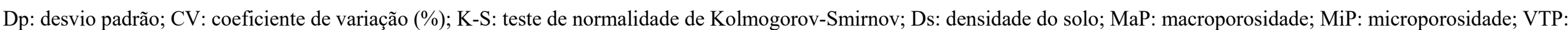

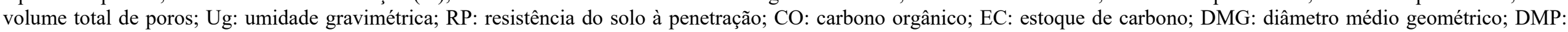
diâmetro médio ponderado. Médias seguidas pela mesma letra maiúscula na coluna não diferem entre si pelo teste de Tukey ( $\mathrm{p}<0,05$ ). 
Tabela 2. Teste de média e estatística descritiva dos atributos do solo na profundidade de 0,05-0,10 m para as áreas com diferentes usos na região de Novo Aripuanã, Amazonas.

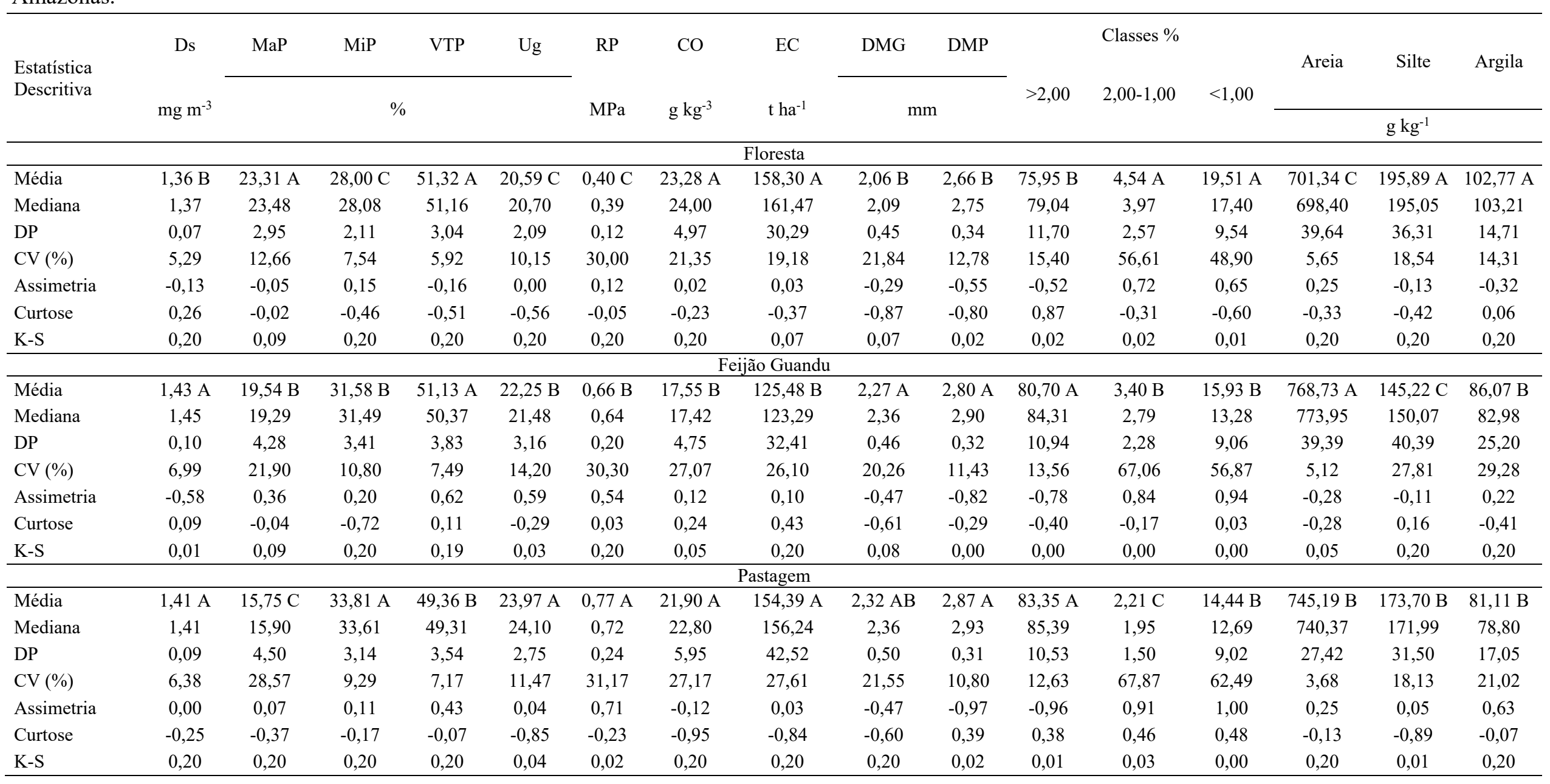

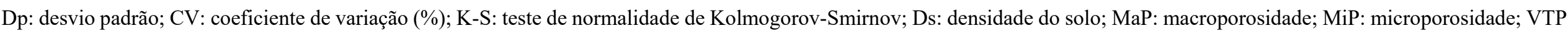

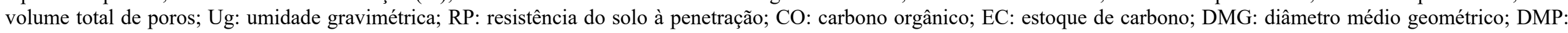
diâmetro médio ponderado. Médias seguidas pela mesma letra maiúscula na coluna não diferem entre si pelo teste de Tukey $(p<0,05)$.

Rev. Ambient. Água vol. 12 n. 2 Taubaté - Mar. / Apr. 2017 


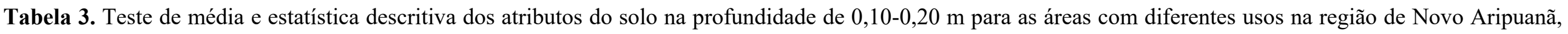
Amazonas.

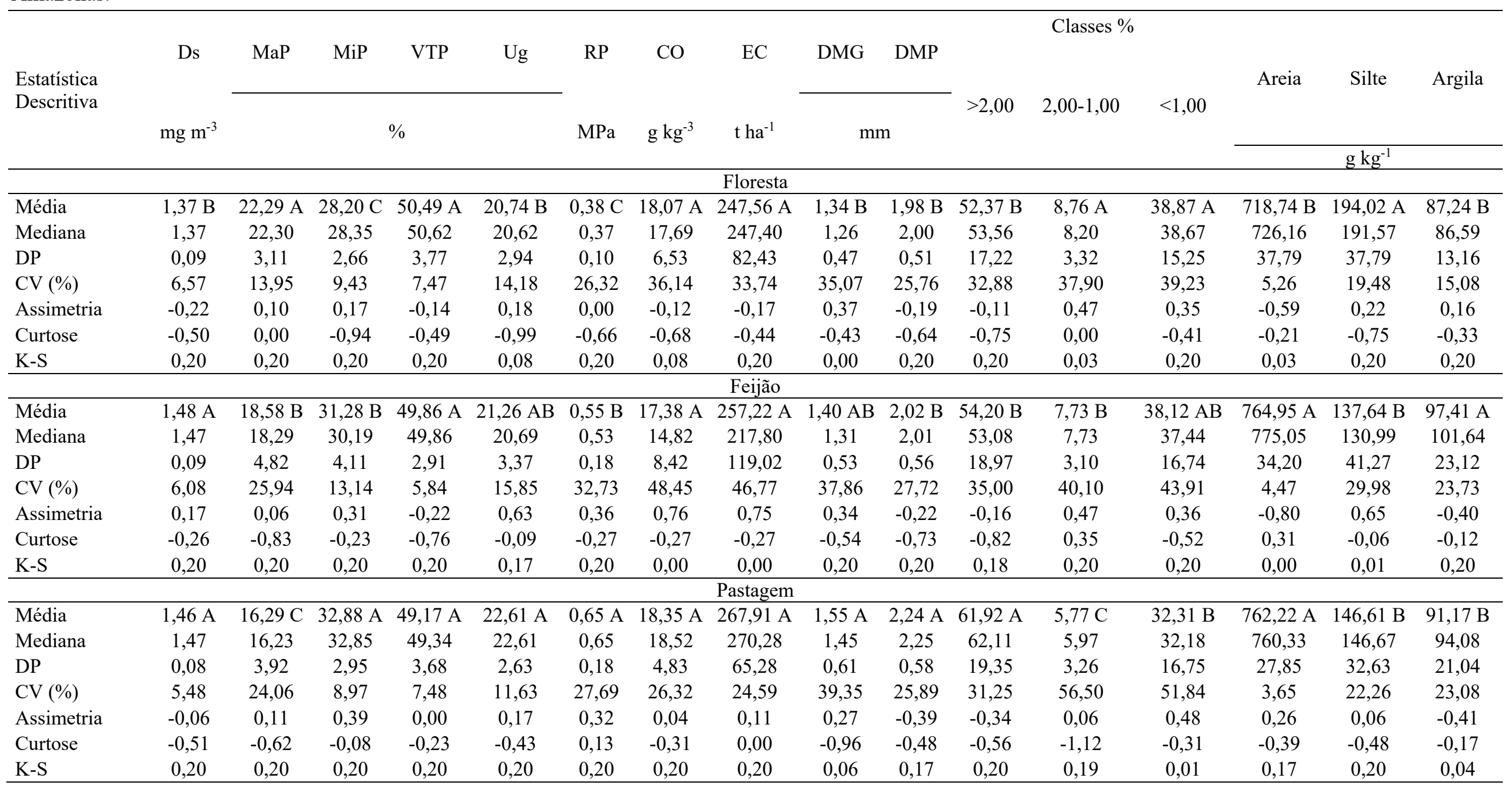

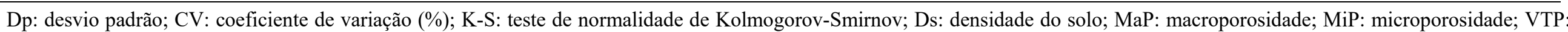

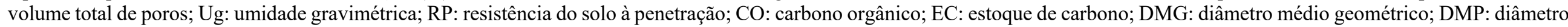
médio ponderado. Médias seguidas pela mesma letra maiúscula na coluna não diferem entre si pelo teste de Tukey $(\mathrm{p}<0,05)$. 
No estudo de gênese do solo, a fração silte passa a constituir como o indicador pela a ação de intemperismo, o que pudemos constatar solos de formação mais jovens que os propostos por Oliveira et al. (2015a).

Por outro lado, os maiores teores de areia sob as áreas de feijão guandu e pastagem se devem provavelmente a fortes chuvas que promovem grandes enxurradas, por essas apresentarem áreas mais abertas, com impacto das gotas de chuva sobre o solo em relação à área sob floresta. A presença de cobertura no solo atua na interceptação das gotas de chuva e evita o desprendimento das partículas do solo. Chuvas de grande intensidade causam maior desagregação do solo e, normalmente, originam escoamento superficial, sendo as partículas menores de solo são mais fáceis de serem transportadas (Volk e Cogo, 2009).

Interações significativas entre os sistemas de uso do solo foram verificadas para as propriedades físicas Ds, MaP, MiP, VTP e Ug, indicando que o uso do solo pouco afetou nas variações dessas propriedades (Tabelas 1,2 e 3 ), para a camada entre 0,00-0,05 m, mas houve mudanças de comportamento aos demais atributos e em camadas subsequentes, com exceção do VTP, CO e EC na camada 0,10-0,20 m. Por outro lado, na camada de 0,00-0,05 m, o solo mantido sob pastagem apresentou-se menos compactada, com menor valor de Ds, além de maiores valores do VTP em relação ao TPA sob floresta e feijão guandu. Mesmo assim, a Ds não diferiu muito em relação ao sistema de uso do solo dentro da mesma camada $(0,00-0,05$ $\mathrm{m})$, mas houve alterações para as camadas $0,05-0,10$ e $0,10-0,20 \mathrm{~m}$, com menor valor de Ds para o uso sob floresta, não havendo diferença entre os sistemas de uso sob feijão guandu e pastagem (Tabelas 1,2 e 3 ).

A ausência de práticas agressivas ao solo em florestas naturais afeta diretamente a estrutura do solo, com baixos valores de Ds (Calonego et al., 2012). Além disso, os mesmos autores afirmam que tanto os altos valores da MO quanto os elevados valores do VTP reduzem também os valores de Ds. Resultados semelhantes foram encontrados para solos não antropogênicos sob o horizonte A (Campos et al., 2012; Santos et al., 2013), mas que apresentaram valores muito baixo em solos antropogênicos (em TPA). Esse fato pode estar relacionado ao tipo de solo, com características físicas que diferem em ralação aos perfis do solo para determinados atributos. Em trabalho realizado por Santos et al. (2011), os autores verificaram valores semelhantes da Ds em TPA com perfil de Neossolo Litólico sob o uso de pastagem, mas com valores baixos em comparação com outros perfis.

Também não houve diferença significativas entre a MaP com os sistemas de uso na camada entre 0,00-0,05 m, que apresentou comportamento semelhante da MiP. No entanto, nas camadas de 0,05-0,10 e 0,10-0,20 m, observou-se maiores valores para a MaP sob o uso de floresta natural e de MiP sob o uso de pastagem, corroborando assim com os valores do VTP para os sistemas de uso do solo, que apresentaram maiores valores em floresta, apesar de haver diferença significativa apenas na camada entre 0,05-0,10 m, com menor valor no sistema de uso sob pastagem.

Esses resultados demonstram que os sistemas de uso do solo contribuem efetivamente para a melhora das condições físicas do solo, promovendo redução da Ds em relação à área de floresta. Resultados semelhantes também foram verificados por Cunha et al. (2011), em avaliar os atributos físicos de solo cultivado com feijão e milho orgânicos sob a influência das plantas de cobertura, que apresentaram, em solo sob mata nativa, menores valores de Ds e MiP e maiores valores de MaP e VTP. Para os autores, essas condições foram propícias devido ao solo não sofrer o trânsito de máquinas e equipamentos ou animais.

Em relação à resistência do solo à penetração (RP), houve diferença significativa sob os sistemas de uso do solo para as três camadas, cujos menores valores da RP estão associados ao uso sob floresta. Esses resultados corroboram também para o baixo valor da Ug e Ds sob a mesma área, apesar de não haver diferença significativa de Ug em relação aos sistemas de uso na camada 0,00-0,05 m. Em estudo sobre a relação entre a umidade do solo e a resistência à 
penetração de um Argissolo Amarelo distrocoeso na região do Recôncavo da Bahia, Silveira et al. (2010) constataram que solos com baixo conteúdo de água, apresentam partículas mais próximas e difíceis de serem separadas, com o aumento da RP. O solo sob floresta apresentou valores de RP menores que $0,50 \mathrm{MPa}$ nos $0,20 \mathrm{~m}$ de profundidade, diferindo dos solos manejados, que apresentaram solos menos compactados apenas nos primeiros $0,05 \mathrm{~m}$ de profundidade. Mesmo assim, esses valores ainda são muito baixos se considerarmos os valores limites definidos do Tavares Filho e Tessier (2009) para solos compactados (RP de 2,0 MPa). Em solos de TPA sob o uso de pastagem, verificou-se valores acima de 2,0 MPa para uma camada de 0,0-0,05 mm (Soares et al., 2015) que, segundo os autores, justifica-se pela compactação do solo devido ao pisoteio animal.

Tanto o CO quanto o EC (Tabelas 1, 2 e 3) houve alterações para os respectivos usos do solo, com maiores valores sob o uso de feijão Guandu na camada 0,00-0,05 m, passando a ter menor valor na camada $0,05-0,10 \mathrm{~m}$, não havendo diferença estatística entre os usos na camada 0,10-0,20 m. Os valores altos de CO sob feijão Guandu na camada 0,00-0,05 m devem estar associados à elevada cobertura vegetal, com mais de oito meses de plantio sem sofrer práticas intensivas no solo e trânsitos de animais.

Altas concentrações de cobertura vegetal verificadas in loco sob o uso do feijão Guandu pode ter favorecido aos maiores teores de CO. Esse resultado difere do proposto por Rossetti et al. (2015), ao determinar o efeito do sistema plantio direto sobre os estoque de carbono e atributos físicos do solo cultivados com soja e milho, e comparação com a mata nativa, identificaram maior concentração de MO sob mata nativa em relação aos demais tratamentos, ao qual os autores associam à deposição contínua de serrapilheira, além da ausência de ação antrópica.

Sob os respectivos usos do solo, o DMG e DMP diferiram estatisticamente, dando maiores valores sob o uso de floresta para a camada $0,00-0,05 \mathrm{~m}$, e sob o uso de pastagem para as camadas de 0,05-0,10 m e 0,10-0,20 m. No entanto, não foram confirmadas correlações significativas entre o DMG/DMP com os atributos CO e EC nas camadas de 0,00-0,05 m e 0,05-0,10 m, com exceção sob o uso de feijão Guandu na camada 0,05-0,10 m, que obteve correlações positivas para o $\mathrm{CO}(0,25$ e 0,27 , respectivamente).

Por outro lado, na camada 0,10-0,20 m, houve correlações significativas entre o DMG/DMP com o CO e EC, com valores de coeficiente de correlação definidos em: 0,39/0,39 e $0,38 / 0,38$, respectivamente, para o uso sob floresta; de $0,36 / 0,36$ e $0,35 / 0,35$, respectivamente, sob o uso sob pastagem; e de 0,30/0,30 e 0,27/0,27, respectivamente, sob o uso de feijão Guandu. Correlações positivas do DMG e DMP com o carbono orgânico foram verificadas por Rozane et al. (2010), indicando sua importância na agregação do solo. Esses resultados também corroboram com os Matos et al. (2008), quando avaliaram a estabilidade de agregados sobre o impacto da adubação orgânica e mineral sobre o solo. $O$ fato de haver perda de correlação dos atributos DMG e DMP com o CO e EC nas camadas mais superficiais, pode ser explicado por práticas como a aração, gradagem e o pisoteio do gado, que promovem a desestruturação dos agregados e a oxidação da matéria orgânica, além do revolvimento do solo para camadas mais profundas.

$\mathrm{Na}$ análise multivariada, foi possível observar os atributos do solo que sofreu maior alteração quando ao uso do solo, em comparação a área sob floresta. A adequação da análise fatorial mostrou-se significativo (KMO igual a 0,78 e p $<0,05$ para o teste de esfericidade de Barlett) para os atributos avaliados. Na análise de componentes principais (ACP), o número de fatores a ser extraído foi estabelecido de forma a explicar acima de $70 \%$ da variância total dos dados (Tabela 4 e Figura 2), que apresentaram autovalores da matriz de covariância superior a um (1) (Manly, 2008), com 4,71 na CP1 e 3,80 na CP2. Do percentual da variância explicada, observou-se que a CP1 é responsável por $42,79 \%$ da variância total, enquanto que a CP2 é responsável por $34,54 \%$. 
Tabela 4. Correlação entre cada componente principal e variáveis analisadas e análise fatorial dos atributos do solo com os fatores rotacionados (Varimax) (Fator 1 e 2 ) correspondentes aos ambientes estudados, na região de Novo Aripuanã, Amazonas.

\begin{tabular}{lccc}
\hline \multirow{2}{*}{ Atributos } & Variância & \multicolumn{2}{c}{ Fatores } \\
\cline { 3 - 4 } & Comum & PC1 & PC2 \\
\hline Ds & 0,79 & $-0,15$ & $-0,86^{*}$ \\
VTP & 0,75 & 0,09 & $0,80^{*}$ \\
Ug & 0,61 & 0,25 & $0,74^{*}$ \\
CO & 0,44 & 0,19 & $0,67^{*}$ \\
Areia & 0,88 & 0,08 & $-0,82^{*}$ \\
Silte & 0,88 & 0,03 & $0,85^{*}$ \\
DMG & 0,91 & $0,95^{*}$ & 0,11 \\
DMP & 1,00 & $0,99^{*}$ & 0,09 \\
$>2,00 \mathrm{~mm}$ & 1,00 & $0,99^{*}$ & 0,08 \\
$2,00-1,00 \mathrm{~mm}$ & 0,77 & $-0,88^{*}$ & 0,06 \\
$<1,00 \mathrm{~mm}$ & 0,99 & $-0,97^{*}$ & $-0,11$ \\
\hline \multicolumn{4}{c}{ Variância } \\
\end{tabular}

Ds: densidade do solo; MaP: macroporosidade; MiP: microporosidade; VTP: volume total de poros; Ug: umidade gravimétrica; RP: resistência do solo à penetração; $\mathrm{CO}$ : carbono orgânico; EC: estoque de carbono; DMG: diâmetro médio geométrico; DMP: diâmetro médio ponderado; >2,00 mm (\%): classe de agregados maior que 2,00 milímetros; $2,00-1,00 \mathrm{~mm}$ : classe de agregados entre 2,00 e 1,00 milímetros; $<1,00 \mathrm{~mm}(\%)=$ classe de agregados menor que 1 milímetros.

A.

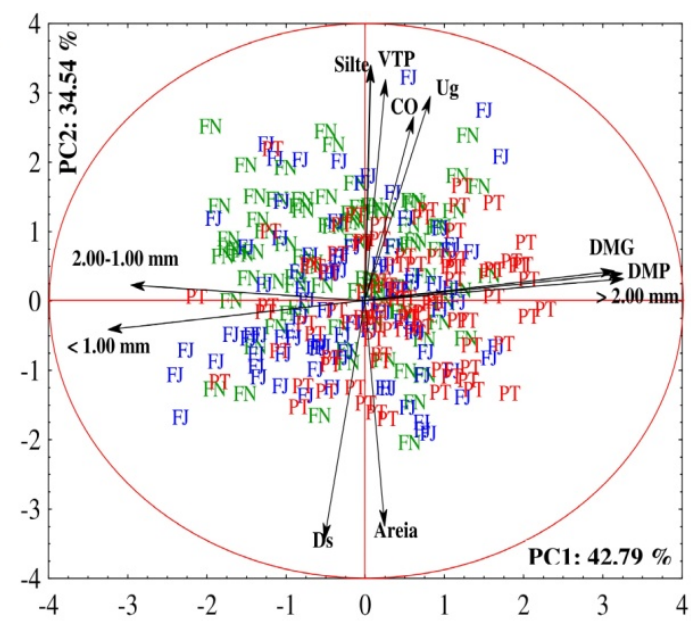

B.

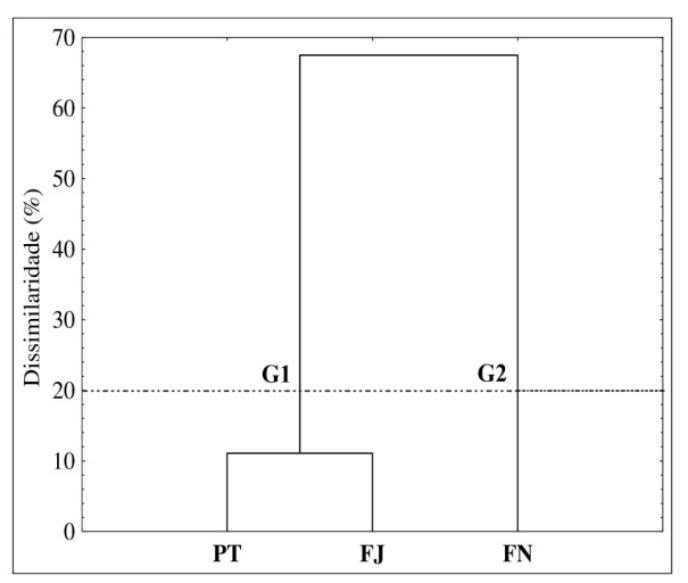

Figura 2. (A) Plano fatorial dos atributos do solo em áreas de Terra Preta Arqueológica sob diferentes usos na região de Novo Aripuanã, Amazonas. Valores padronizados de tal forma que a média é zero e as distancias entre os escores é medido pelo desvio padrão. (B) Dendrograma de agrupamentos dos usos do solo em Terra Preta Arqueológica com linha de corte de $20 \%$, de acordo com os atributos do solo com cargas fatoriais superiores a 0,70 . FN: floresta; FJ: feijão guandu; PT: pastagem. 
Tanto a primeira quanto a segunda fator (Tabela 4) tem percentual de explicação para as características estruturais, mecânica e granulométrica do solo. Assim, a discriminação entre os ambientes diz respeito a essas características, com CP1 representando as características de estabilidade dos agregados do solo (DMG, DMP e classes de agregados $>2,00 \mathrm{~mm}, 2,00-1,00$ $\mathrm{mm}$ e $<1,00 \mathrm{~mm}$ ), enquanto a CP2 às características estruturais do solo, textura e do carbono orgânico (Ds, VTP, Ug, CO, teor de areia e silte).

Na Figura 2A está representado o plano fatorial da distribuição dos escores das diferentes áreas estudadas e da disposição das cargas fatoriais dos atributos do solo formado pelos PC1 e PC2. Observa-se maior adensamento dos escores da floresta no primeiro e segundo quadrante da Figura 2A, o que discrimina a área sob floresta que obtiveram valores dos atributos Ds, VTP, Ug, CO, teor de areia e silte acima da média. Por outro lado, as áreas sob feijão Guandu e pastagem apresentam-se mais distribuído entre o primeiro, terceiro e o quarto quadrante, com atributos que apresentam caracterizados estruturais acima da média, assim como características mecânicas, granulométricas e carbono orgânico abaixo da média.

Utilizando os atributos na análise de agrupamentos (Figura 2B), e considerando a linha de corte $20 \%$ da medida de dissimilaridade, observa-se a formação de dois grupos distintos, com as áreas sob feijão Guandu e pastagem consideradas estatisticamente iguais no que diz respeito ao comportamento dos atributos físicos e carbono orgânico do solo, que é confirmada pela análise fatorial.

Os atributos apresentaram coeficiente de variação (CV) com valores variando de baixo, moderara e alto (Tabelas 1, 2 e 3), segundo os critérios de Warrick e Nielsen (1980), e isso como sendo um indicativo da heterogeneidade dos dados. Verificou-se que em todas as áreas estudadas, e em suas respectivas profundidades, os atributos apresentaram predominância de CV baixo a moderado, corroborando com resultados de Aquino et al. (2015), que avaliaram os atributos físicos em ambientes utilizando o semivariograma escalonado. Também foram verificados comportamentos semelhantes em outros trabalhos com variabilidade espacial dos atributos físicos do solo (Oliveira et al., 2015a; Santos et al., 2012).

Os atributos Ds, MiP, VTP, Ug e teor de areia, apresentaram CV baixo (até $11,63 \%$ ), com exceção a MiP e Ug, que mostraram comportamento de CV mediano sob o uso do feijão Guandu (na camada $0,10-0,20 \mathrm{~m}$ para a MiP e nas três camadas para $\mathrm{Ug}$ ), sendo o último sob o uso de floresta na camada 0,10-0,20 m. Os atributos DMG, DMP e classe de agregados $>2,00 \mathrm{~mm}$, apresentaram $\mathrm{CV}$ de baixo à mediano nas duas primeiras camadas, sob todos os usos do solo, e alta na camada subsequente $(0,10-0,20 \mathrm{~m})$, com exceção do DMG na área de feijão Guandu, que mostrou um CV alto na camada 0,00-0,05 m. Os demais atributos apresentaram CV de mediana a alta em todos os usos e camadas adotadas, sendo a RP com CV todas altas, com valores entre $30 \%$ a $44,90 \%$. Em geral, a área sob floresta foi o que apresentou mais homogeneidade $(\mathrm{CV}=17,93 \%)$, seguido de pastagem $(\mathrm{CV}=21,31 \%)$, ambos com $\mathrm{CV}$ mediano, enquanto que na área sob feijão Guandu, o coeficiente de variação foi de 23,99\%, com alta variabilidade, sendo mais heterogêneo quando comparadas às outras áreas.

Dada a comportamento do CV para os atributos do solo, este pode comparar a variabilidade dos atributos com unidades diferentes. No entanto, para a variabilidade espacial, o semivariograma escalonado foi utilizado, o que observou uma variabilidade espacial na maioria dos atributos, com modelo de ajuste exponencial e esférica (Figuras 3, 4 e 5). 


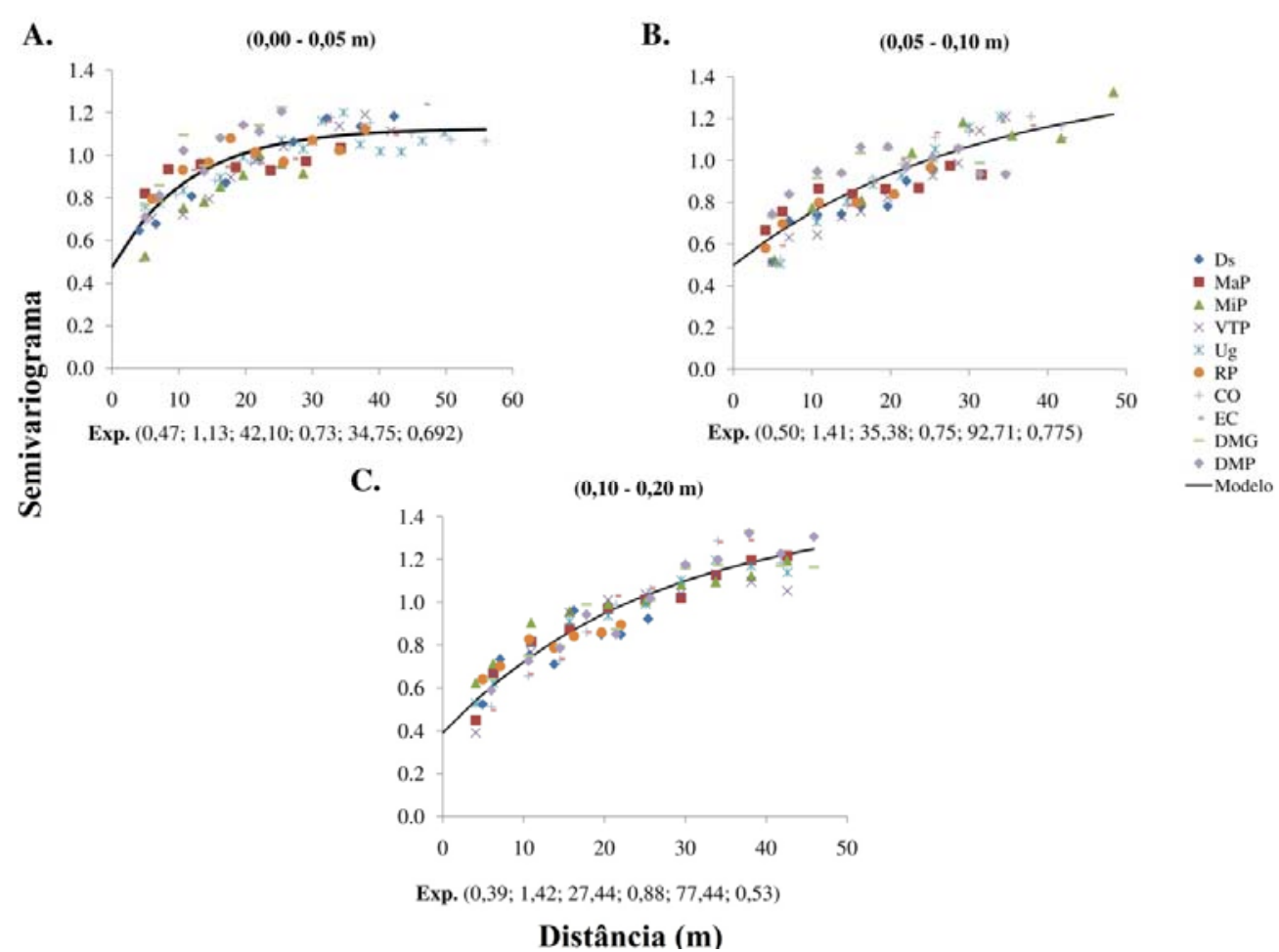

Figura 3. Parâmetros e modelos dos semivariogramas escalonados ajustados aos atributos do solo em áreas de TPA sob floresta na região de Novo Aripuanã, Amazonas. [modelo (efeito pepita; patamar; GDE; R2; alcance; resíduo)]. Esf.: Esférico; Exp.: exponencial; GDE: grau de dependência espacial; $\mathrm{R}^{2}$ : coeficiente de determinação.

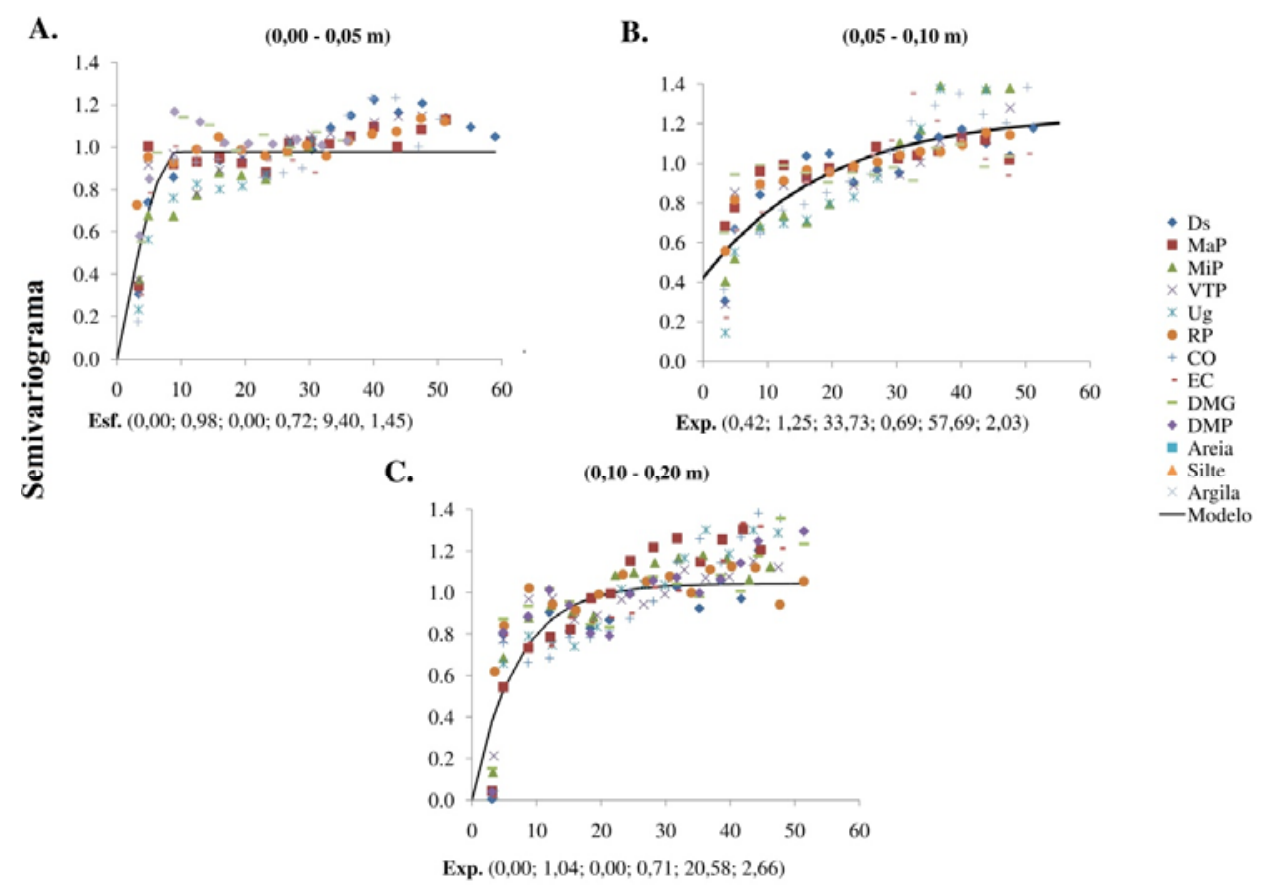

Distância (m)

Figura 4. Parâmetros e modelos dos semivariogramas escalonados ajustados aos atributos do solo em áreas de TPA sob feijão na região de Novo Aripuanã, Amazonas. [modelo (efeito pepita; patamar; GDE; R2; alcance; resíduo)]. Esf.: Esférico; Exp.: exponencial; GDE: grau de dependência espacial; $\mathrm{R}^{2}$ : coeficiente de determinação. 


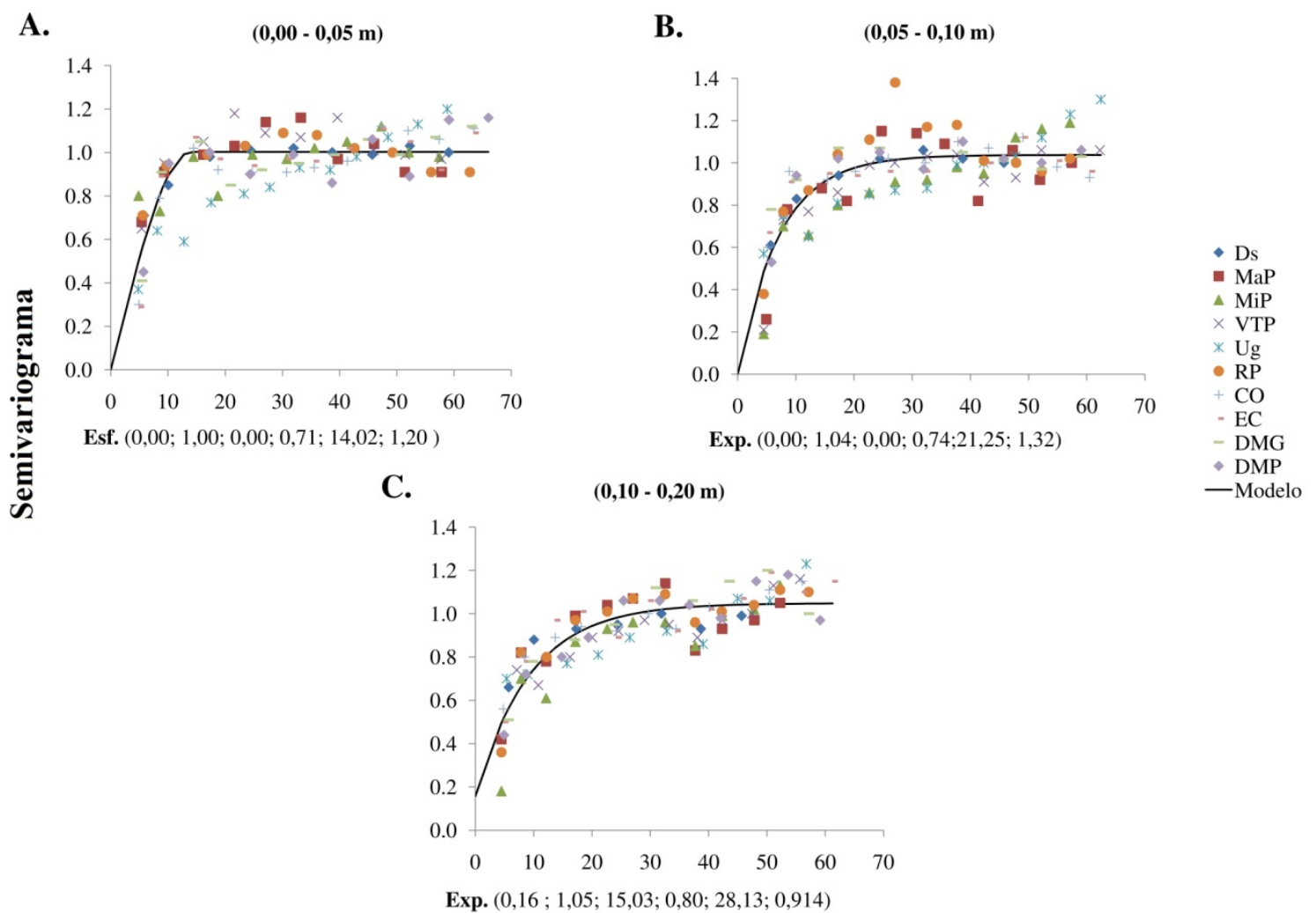

Distância (m)

Figura 5. Parâmetros e modelos dos semivariogramas escalonados ajustados aos atributos do solo em áreas de TPA sob pastagem na região de Novo Aripuanã, Amazonas. [modelo (efeito pepita; patamar; GDE; R2; alcance; resíduo)]. Esf.: Esférico; Exp.: Exponencial; GDE: grau de dependência espacial; $\mathrm{R}^{2}$ : coeficiente de determinação.

Houve mudança de comportamento dos padrões de variabilidade espacial em comparação a área de floresta. O grau de dependência espacial, segundo a classificação de Cambardella et al. (1994), foram fortes em áreas sob feijão Guandu e pastagem nas camadas adotadas (Figuras 4 e 5), com exceção a área de feijão Guandu na camada 0,05-0,10 m, que apresentaram dependência espacial moderada. Por outro lado, a área sob floresta apresentou dependência moderara (Figura 3). Todos esses resultados estão de acordo com os trabalhos de Aquino et al. (2015) e Oliveira et al. (2015a), em se tratando de variabilidade dos atributos do solo em áreas de TPA ou solos adjacentes.

Com base aos ajustes do modelo do semivariograma escalonado, verificou-se comportamento semelhante dos atributos avaliados em relação à área de floresta com as demais áreas. Houve predominância dos modelos exponenciais (Figuras 3, 4 e 5) para o ajuste do semivariograma escalonado, levando em consideração o menor resíduo. O Modelo esférico foi ajustado apenas nas áreas de feijão Guandu e pastagem para a camada de 0,00-0,05 m. Esse resultado corrobora com outras pesquisas, quando avaliado os atributos físicos e químicos em áreas de TPA sob cultivo, onde foram verificados modelos esféricos nas camadas de $0,00-0,10$ $\mathrm{m}$ e de 0,00-0,20 m, respectivamente (Aquino et al., 2015; Oliveira et al., 2015a). O modelo exponencial mostra um comportamento dos atributos com variações mais erráticas (menos contínuas), quando comparadas aos modelos de ajuste esférico, por este apresentar uma variabilidade mais contínua (Isaaks e Srivastava, 1989). Assim, os modelos tiveram bons ajustes ao semivariograma escalonado, com coeficientes de determinação $\left(\mathrm{R}^{2}\right)$ variando entre 0,69 em área de feijão Guandu na camada de 0,05-0,10 m, a 0,88 em área de floresta na camada de $0,10-0,20 \mathrm{~m}$. 
Avaliando os valores do alcance ajustado (Figuras 3, 4 e 5), observou-se que em áreas sob feijão Guandu, com coletas de solos em uma malha com distância mínima de quatro metros, houve menor alcance para a independência da variância entre os pares (patamar), com relação aos atributos do solo, com valores de $9,40 \mathrm{~m}$ e 20,58 $\mathrm{m}$ para as camadas de $0,00-0,05 \mathrm{~m}$ e 0,10 $0,20 \mathrm{~m}$, respectivamente (com exceção à camada de 0,05-0,10 m, que obteve valor de 57,69 m, sendo superior à área sob pastagem para a mesma profundidade). Isso mostra alta variabilidade dos atributos do solo para pequenas distâncias de coleta, fortalecendo a justificativa de maior heterogeneidade dos atributos do solo em relação às demais áreas.

Em área sob pastagem, os alcances foram de 14,02 m, 21,25 e 28,13 m, em suas respectivas camadas, sendo uma malha com distância de coleta mínima de oito (8) metros. Para a área sob floresta, por outro lado, evidenciou um comportamento mais homogêneo para todas as camadas, em comparação as outras áreas, com dependência de correlação espacial chegando a alcance de $34,75 \mathrm{~m}, 92,71 \mathrm{~m}$ e $77,44 \mathrm{~m}$, respectivamente.

\section{CONCLUSÕES}

Houve mudança significativa dos atributos físicos Ds, VTP, MaP e MiP em relação ao tipo de cobertura para camadas até $20 \mathrm{~cm}$ de profundidade. A RP apresentou seu menor valor sob floresta, consistente com os baixos valores de Ug e Ds. Os respectivos usos do solo também promoveram alterações aos valores de $\mathrm{CO}$ e EC, com melhores resultados em áreas sob o uso de feijão guandu e floresta.

$\mathrm{Na}$ análise multivariada, as áreas de feijão guandu e pastagem apresentaram comportamentos semelhantes, com estabilidades dos agregados acima da média, assim como características estruturais, textura e do carbono orgânico abaixo da média.

O modelo exponencial no semivariograma escalonado mostrou grau de dependência espacial forte para os usos do solo sob feijão guandu e pastagem e moderaro para a área sob floresta. A área sob feijão guandu apresentou maior heterogeneidade, com menor alcance de independência espacial da variância entre os pares.

\section{AGRADECIMENTOS}

Os autores agradecem a FAPEAM (Edital 030/2013 - UNIVERSAL AMAZONAS), ao DINTER/CAPES (Edital CAPES 013/2012) e ao Programa de Pós-Graduação em Física Ambiental, pelo financiamento e apoio da pesquisa.

\section{REFERÊNCIAS}

ANDRADE, R.S.; STONE, L.F.; SILVEIRA, P.M. Culturas de cobertura e qualidade física de um Latossolo em plantio direto. Revista Brasileira Engenharia Agrícola e Ambiental, v. 13, p. 411-8, 2009.

AQUINO, R.E.; CAMPOS, M.C.C.; MARQUES JUNIOR, J.; OLIVEIRA, I.A.; TEIXEIRA D.D.B.; CUNHA, J.M. Use of scaled semivariograms in the planning sample of soil physical properties in southern Amazonas, Brazil. Revista Brasileira de Ciência do Solo, v. 39, p. 21-30, 2015. http://dx.doi.org/10.1590/01000683rbes20150524

BRASIL. Ministério das Minas e Energia. Projeto RADAM brasil - Folha SB. 20, Purus. Rio de Janeiro, 1978. 561p.

Rev. Ambient. Água vol. 12 n. 2 Taubaté - Mar. / Apr. 2017 
CALONEGO, J.C.; SANTOS, C.H.; TIRITAN, C.S.; CUNHA JÚNIOR, J.R. Estoque de carbono e propriedades físicas de solos submetidos a diferentes sistemas de manejo. Revista Caatinga, v. 24, p. 128-35, 2012.

CAMBARDELLA, C.A.; MOORMAN, T.B.; NOVAK, J.M.; PARKIN, T.B.; KARLEN, D.L.; TURCO, R.F. et al. Field-scale variability of soil properties in Central Iowa. Soil Science Society of America Journal, v. 58, p. 1501-11, 1994. http://dx.doi.org/10.2136/sssaj1994.03615995005800050033x

CAMPOS, M.C.C.; SANTOS, L.A.C.; SILVA, D.M.P.; MANTOVANELLI, B.C.; SOARES, M.D.R. Caracterização física e química de terras pretas arqueológicas e de solos não antropogênicos na região de Manicoré, AM. Revista Agro@mbiente On-line, v. 6, p. 102-9, 2012. http://dx.doi.org/10.18227/1982-8470ragro.v6i2.682

CEDDIA, M.B.; VIEIRA, S.R.; VILLELA, A.L.O.; MOTA, L.S.; ANJOS, L.H.C.; CARVALHO, D.F. Topography and spatial variability of soil physical properties. Scientia Agrícola, v. 66, p. 338-52, 2009. http://dx.doi.org/10.1590/S010390162009000300009

CRESSIE, N. Statistics for spatial data. New York: John Wiley, 1991.

CUNHA, E.Q.; STONE L.F.; MOREIRA, J.A.A.; FERREIRA, E.P.B.; DIDONET, A.D.; LEANDRO, W.M. Sistemas de preparo do solo e cultura de cobertura na produção orgânica de feijão e milho. Revista Brasileira de Ciência do Solo, v. 35, p. 589-602, 2011.

EMBRAPA. Centro Nacional de Pesquisa do Solo. Manual de métodos de análise de solo. 2. ed. Rio de Janeiro: Embrapa Solo; 2011.

IORI, P.; DIAS JÚNIOR, M.S.; SILVA, R.B. Resistência do solo à penetração e ao cisalhamento em diversos usos do solo em áreas de preservação permanente. Bioscience Journal, v. 28, p. 185-95, 2012.

ISAAKS, E.H.; SRIVASTAVA, R.M. An introduction to applied geoestatistics. New York: Oxford University Press, 1989.

KÄMPF, N.; KERN, D.C. O solo como registro da ocupação humana pré-histórica na Amazônia. In: VIDAL-TORRADO, P.; ALLEONI, L.R.F.; COOPER, M.; SILVA, A.P.; CARDOSO, E.J. (Orgs.). Tópicos em ciência do solo. Viçosa: Sociedade Brasileira de Ciência do Solo, 2005. v. 5. p.277-320.

KEMPER, W.D.; CHEPIL, W.S. Size distribution of aggregates. In: BLACK, C.A.; EVANS, D.D.; WHITE, J.L.; ENSMINGER, L.E.; CLARK, F.E. (Eds.). Methods of soil analysis - Physical and mineralogical properties, including statistics of measurement and sampling. Madison: American Society of Agronomy,1965. p.499-510.

MATOS, E.S.; MENDONÇA, E.S.; LEITE, L.F.C.; GALVÃO, J.C.C. Estabilidade de agregados e distribuição de carbono e nutrientes em Argissolo sob adubação orgânica e mineral. Pesquisa Agropecuária Brasileira, v. 43, p. 1221-30, 2008.

MANLY, B.J.F. Métodos estatísticos multivariados: uma introdução. 3. ed. Porto Alegre: Bookman, 2008.

MELO, V.F.; SCHAEFER, C.E.G.R. Matéria orgânica em solos desenvolvidos de rochas máficas no nordeste de Roraima. Acta Amazonica, v. 39, p. 53-60, 2009. 
OLIVEIRA, I.A.; CAMPOS, M.C.C.; SOARES, M.D.R.; AQUINO, R.E.; MARQUES JUNIOR, J.; NASCIMENTO, E.P. Variabilidade espacial de atributos físicos em um CambissoloHáplico, sob diferentes usos na região do Amazonas. Revista Brasileira de Ciência do Solo, v. 37, p. 1103-12, 2013. http://dx.doi.org/10.1590/S010006832013000400027

OLIVEIRA, I.A.; MARQUES JUNIOR, J.; CAMPOS, M.C.C.; AQUINO, R.E.; FREITAS, L.; SIQUEIRA, D.S. et al. Variabilidade espacial e densidade amostral da suscetibilidade magnética e dos atributos de Argissolos da região de Manicoré, AM. Revista Brasileira de Ciência do Solo, v. 39, p. 668-81, 2015a.

OLIVEIRA, I.A.; CAMPOS, M.C.C.; FREITAS, L.; SOARES, M.D.R. Caracterização de solos sob diferentes usos na região sul do Amazonas. Acta Amazonica, v. 45, n. 1, p. 1-12, 2015b. http://dx.doi.org/10.1590/1809-4392201400555

ROBERTSON, G.P. GS+: Geostatistics for the environmental sciences. Gamma design software. Plainwell: MI, 1998.

ROSSETTI, K.V.; CENTURION, J.F. Estoque de carbono e atributos físicos de um Latossolo em cronossequência sob diferentes manejos. Revista Brasileira de Engenharia Agrícola e Ambiental, v. 19, p. 252-8, 2015. http://dx.doi.org/10.1590/18071929/agriambi.v19n3p252-258

ROZANE, D.E.; CENTURION, J.F.; ROMUALDO, L.M.; TANIGUCHI, C.A.K.; TRABUCO, M.; ALVES, A.U. Estoque de carbono e estabilidade de agregados de um Latossolo Vermelho Distrófico, sob diferentes manejos. Bioscience Journal, v. 26, p. 24$32,2010$.

SANTOS, L.A.C.; CAMPOS, M.C.C.; BERGAMIN, A.C.; SILVA, D.M.P.; MENDONÇA JÚNIOR, A.F. Característica física de seis sitos de terras pretas arqueológicas na região de Apuí-AM. Revista Verde, v. 6, p. 167-74, 2011.

SANTOS, K.S.; MONTENEGRO, A.A.A.; ALMEIDA, B.G.; MONTENEGRO, S.M.G.L.; ANDRADE, T.S.; FONTES JÚNIOR, R.V.P. Variabilidade espacial de atributos físicos em solos do vale aluvial no semiárido de Pernambuco. Revista Brasileira de Engenharia Agrícola e Ambiental, v. 16, p. 828-35, 2012.

SANTOS, L.A.C.; CAMPOS, M.C.C.; AQUINO, R.E.; BERGAMIN, A.C.; SILVA, D.M.P.; MARQUES JUNIOR, J. et al. Caracterização de Terras Pretas Arqueológicas no Sul do Estado do Amazonas. Revista Brasileira de Ciência do Solo, v. 37, p. 825-36, 2013. http://dx.doi.org/10.1590/S0100-06832013000400001

SILVA, A.R.; SILVA, L.L.; FRAZÃO, J.J.; SALGADO, F.H.M.; SILVA, M.C.; CORRECHEL, V. Resistência mecânica à penetração do solo com diferentes coberturas vegetais sob sistema. Revista Cientifica Eletrônica da Agronomia, v. 22, p. x-x, 2012.

SILVA, F.F.; FREDDI, O.S.; CENTURION, J.F.; ARATANI, R.G.; ANDRIOLI, F.F.; ANDRIOLI, I. Propriedades físicas de um Latossolo Vermelho cultivado no sistema plantio direto. Revista Irriga, v. 13, p. 191-204, 2008.

SILVEIRA, D.C.; FILHO, J.F.M; SACRAMENTO, J.A.S.; SILVEIRA, E.C.P. Relação umidade versus resistência à penetração para um Argissolo Amarelo Distrocoeso no Recôncavo da Bahia. Revista Brasileira de Ciência do Solo, v. 34, p. 659-67, 2010. 
SOARES, D. R.; CAMPOS, M. C. C.; SOUZA, Z. M.; BRITO, W. B. M.; FRANCISCON, U.; CASTIONI, G. A. F. Variabilidade espacial dos atributos físicos do solo em área de Terra Preta Arqueológica sob pastagem em Manicoré, AM. Revista de Ciências Agrárias, v. 58, n. 4, p. 434-441, 2015.

STATSOFT INC. Statistica - data analysis software system. Tulsa, 2004.

TAVARES FILHO, J.; TESSIER, D. Compressibility of oxisol aggregates under no-till in response to soil water potential. Revista Brasileira de Ciência do Solo, v. 33, n. 6, p. 1525-1533, 2009. http://dx.doi.org/10.1590/S0100-06832009000600002

VIANA, E.T.; BATISTA, M.A.; TORMENA, C.A.; COSTA, A.C.S.; INOUE, T.T. Atributos físicos e carbono orgânico em Latossolo Vermelho sob diferentes sistemas de uso e manejo. Revista Brasileira de Ciência do Solo, v. 35, p. 2105-14, 2011.

VOLK, L.B.S.; COGO, N.P. Relações entre tamanho de sedimentos erodidos, velocidade da enxurrada, rugosidade superficial criada pelo preparo e tamanho de agregados em solo submetido a diferentes manejos. Revista Brasileira de Ciência do Solo, v. 33, p. 1459$71,2009$.

WARRICK, A.W.; NIELSEN, D.R. Spatial variability of soil physical properties in the field. In: HILLEL, D. (Ed.). Applications of soil physics. New York: Academic Press, 1980. p.319-44.

WHITE, P.J.; CRAWFORD, J.W.; ÁLVAREZ, M.C.D.; MORENO, R.G. Soil Management for Sustainable Agriculture. Applied and Environmental Soil Science, v. 2012, p. 1-3, 2012. http://dx.doi.org/10.1155/2012/850739

YEOMANS, J.C.; BREMNER, J.M. A rapid and precise method for routine determination of organic carbon in soil. Communications in Soil Science and Plant Analysis, v. 19, p. 1467-76, 1988. http://dx.doi.org/10.1080/00103628809368027 